\title{
UMA DUPLA CONSTRUÇÃO DISCURSIVA DA ESTRADA DE FERRO MADEIRA-MAMORÉ PELAS FOTOGRAFIAS DE DANA MERRILL
}

A DOUBLE DISCURSIVE CONSTRUCTION OF THE MADEIRA-MAMORÉ RAILROAD BY DANA MERRILL'S PHOTOGRAPHS

\author{
Patrícia Helena dos Santos Carneiro' \\ Júlio César Barreto Rocha ${ }^{2}$ \\ Antônio Cândido da Silva ${ }^{3}$
}

\begin{abstract}
Resumo
A contratação do fotógrafo Dana Merrill pelo empresário Percival Farquhar obedecia ao propósito de buscar argumentos que justificassem investimentos na construção da Ferrovia Madeira-Mamoré, sobretudo para explicar a justa aplicação dos recursos financeiros captados. Contudo, mais do que promover um discurso fotográfico descritivo, ao perceber que está em uma fronteira civilizacional diferenciada, em termos de origens dos tipos humanos, em contato com autóctones e colonos brasileiros, em condições específicas, Dana Merrill procura retratar a saga, através das suas lentes, querendo por um lado contemplar o pleito do empresário, mas por outro lado demonstrando interesse em difundir um ideal de colonização tecnológica, no embate entre a natureza e a perseverança humana. Considera-se ser o enfoque escolhido pelo fotógrafo uma combinação, que toma um viés voltado aos propósitos de quem o contratou com os próprios interesses do fotógrafo. Por esta perspectiva trabalham-se aspectos teóricos de Bhabha e de Eagleton, para realizar uma análise cultural, municiada de ferramentas complementares, como as oriundas da Análise do Discurso de Pêcheux, dispostas a obter o reconhecimento da dupla resultante da interpretação político-cultural. Noutras palavras, o discurso histórico-visual é visto num âmbito semiótico, apropriado para compreender uma discursividade artística que possuía vistas concretas especiais, no local, pelo autor, podendo ser desvelado o próprio universo cultural da dupla compreensão da época. Ao final, oferece-se a inserção de imagens que ilustram a análise referente ao tema ora apresentado.
\end{abstract}

Palavras-chave: Fotografia; Amazônia; História.

\begin{abstract}
The hiring of photographer Dana Merrill by businessman Percival Farquhar obeyed the purpose of seeking arguments that justified investments in the construction of the Madeira-Mamoré Railway, mainly to explain the fair application of the financial resources raised. However, more than promoting a descriptive photographic discourse, when realizing that he is on a differentiated civilizational frontier, in terms of origins of human types, in contact with Brazilian natives and colonists, under specific conditions, Dana Merrill seeks to portray the saga, through the his lenses, wanting, on the one hand, to contemplate the plea of the entrepreneur, but on the other hand showing interest in spreading an ideal of technological colonization, in the clash between Nature and human perseverance. The approach chosen by the photographer is considered to be a combination that takes a bias towards the purposes of those who hired him with the photographer's own interests. From this perspective, theoretical aspects of Bhabha and Eagleton are used to carry out a cultural analysis, equipped with complementary tools, such as those derived from Pêcheux's Discourse Analysis, willing to obtain recognition from the pair resulting from the political-cultural interpretation. In other words, the historical-visual discourse is seen in a semiotic context, appropriate to understand an artistic discourse that had special concrete views, on the spot, by the author, and the cultural universe of the double understanding of the time can be unveiled. At the end, it is offered the insertion of images that illustrate the analysis related to the theme now presented.
\end{abstract}

Keywords: Photography; Amazon; History.

\footnotetext{
${ }^{1}$ Docente da Universidade Federal de Rondônia (UNIR), Departamento de Línguas Estrangeiras, Campus de Porto Velho. Doutora em Direito pela Universidade de Santiago de Compostela / UERJ. Vice-líder do Grupo de Pesquisa Filologia e Modernidades. Coordenadora do Projeto de Pesquisa "Direito e Literatura: Amazônia e o Olhar do Literário sobre os Direitos Humanos” (PIBIC-CNPq/UNIR). E-mail: patriciacarneiro@unir.br

${ }^{2}$ Docente da Universidade Federal de Rondônia, Departamento de Letras Vernáculas, leciona no Mestrado Acadêmico em Letras. Doutor pela Universidade de Santiago de Compostela / UFRJ. Líder do Grupo de Pesquisa Filologia e Modernidades, é vice-coordenador do Projeto de Pesquisa "Direito e Literatura". juliorocha@unir.br ${ }^{3}$ Bacharel e Licenciado em Letras, Língua Portuguesa, pela Universidade Federal de Rondônia (2006), é autor de obras literárias e na área de História. Concluiu Mestrado em História e Estudos Culturais, dedica-se à Literatura com diversas obras (livros e crônicas) publicadas com o olhar voltado à cultura amazônica. E-mail: a.candido.silva@hotmail.com
} 
Depois dessa frustração e dessa derrota, comandada por George Earl Church, entra em cena outro empresário: Percival Farquhar, que, em 1908, assumiu a tarefa e recebeu como concessão a empreitada de construir a Estrada de Ferro Madeira-Mamoré (EFMM). Com empreendimentos funcionando no Brasil, em São Paulo e no Rio Grande do Sul, concorrendo com outros grandes empresários e captadores de investimentos, a promessa de lucratividade não era escassa, porém não era uma atividade simples para Farquhar, sobretudo considerando a transitoriedade dos governos brasileiros naquela virada de século.

Após duas tentativas fracassadas de construção, a Estrada de Ferro Madeira-Mamoré estava sendo, sem dúvida alguma, o mais difícil, o mais dispendioso empreendimento ferroviário de tantos quantos alimentaram as unidades nacionais pelo Globo, e também aquele que mais ceifou vidas de trabalhadores, nos seu quatro anos de trabalho das cachoeiras do Madeira até as proximidades da densa selva amazônica boliviana. Não era fácil explicar os motivos de manter essa verdadeira saga a tantos quantos criticavam os empreendimentos Farquhar, que precisaria de uma explicação profissional que complementasse retoricamente o seu trabalho de empresário.

A contratação de um fotógrafo para documentar as várias etapas da construção da Ferrovia Madeira-Mamoré foi sugerida, portanto, como um fato consequente com aqueles tempos, quando, nas palavras de Gauld, "Farquhar enviou o fotógrafo Dana B. Merrill, de Nova York, para uma estada de dois anos, em que tirou cerca de 300 fotos de todas as fases do épico trabalho"4.

O fotógrafo Dana Bernard Merrill empregava na sua arte aquilo que existia de mais moderno como equipamento fotográfico, utilizado por profissionais que tivessem que se deslocar para registrar algumas grandes obras de interesse público. Devemos recordar que, na época, em 1905, a National Geographic havia lançado a sua primeira reportagem fotográfica. Este modelo passou a ser um exemplo de observação realística, que substituiu as gravuras e os desenhos como representação de primeira mão da realidade.

Embora Merrill tenha sido contratado para fazer trezentas fotografias, consta que ele alcançou, aproximadamente, dois mil retratos, se considerarmos que existem, hoje, vários

\footnotetext{
${ }^{4}$ GAULD. Charles Anderson. Farquhar. O Último Titã. Tradução Eliana Nogueira do Vale. São Paulo: Editora de Cultura, 2006. p. 182.
} 
acervos, interesse inicialmente de pessoas que compraram ou receberam em doação as fotos não selecionadas por Farquhar. ${ }^{5}$

A perspectiva deste presente texto, que verifica as bases concretas para a contratação do fotógrafo Dana Merrill, claramente com o objeto de documentar positivamente a construção do chamado "Complexo Ferroviário Madeira-Mamoré”, possui as vistas postas em analisar as fotografias por prismas diferenciados, ou seja, admitindo que o próprio fotógrafo possuía outra intencionalidade artística sua, que faz ressaltar no viés recolhido nas suas fotografias. É certo que ao destacar o regional rondoniano no "Complexo Madeira"6, não implicou trabalharmos descolados de aspectos internacionais ou nem mesmo esquecendo as variáveis multinacionais empregadas no teatro regional e local. O ponto de vista de quem é citado é trazido à baila justamente para preservar o momento de identificação dos sujeitos, na trama histórica localizada.

Entendemos, com Walter Benjamin, que "a produção de conhecimento histórico é vibrante e reverbera em direção ao passado a partir das reivindicações feitas no presente" ", e este texto ancora o seu argumento em teoria de discurso contemporânea, a mais de cem anos depois da "saga" da Estrada de Ferro Madeira-Mamoré (EFMM), mas não perde de vista o viés da sua época discursiva, que é justamente o interesse de fazer da fotografia especializada de Dana Merrill o carro-chefe argumentativo das propostas de conduzir o progresso até a "selvageria" das matas amazônicas, na sua última fronteira. Como as vias férreas mesmas, paralelamente, Dana Merrill faz acompanhar ambas as suas intencionalidades nas fotografias que realiza: a justificativa que desejava Farquhar e o retrato da saga.

A presente reconstrução do quadro histórico da EFMM parte, assim, do ideal da divisão das narrativas, a contratada e a autoral, com descentramento do interesse políticoadministrativo, dando importância a um aspecto político-cultural de época, num recorte interessado em uma análise com interesse global. Claro que nem tudo que se apresenta

\footnotetext{
${ }^{5}$ GAULD. Charles Anderson. Farquhar. O Último Titã. Tradução Eliana Nogueira do Vale. São Paulo: Editora de Cultura, 2006, p. 182-183-187-208-211; ASHMEAD, P. H. Bulletin of the Pan American Union. Vol. XXXII. January-June, Washington, D.C., 1911. p. 432-452.

${ }^{6}$ ALMEIDA, Alfredo Vagner Berno de (Org.). Conflitos sociais no “Complexo Madeira”. In: Projeto Nova Cartografia Social da Amazônia. Manaus: UEA Edições, 2009. Disponível em: https://www.academia.edu/9030621/Conflitos_sociais_no_Complexo_Madeira; Acesso em 14 jun. 2020.

${ }^{7}$ SANTOS, Evandro e BIAZO, Glauber Cícero Ferreira. Teoria da História e História da Historiografia: Debates e desafios do conhecimento histórico no século XXI. Dossiê. V. 10 n. 1 (2018). Canoa do Tempo. Revista do Programa de Pós-Graduação em História da Universidade Federal do Amazonas (UFAM). Manaus: UFAM, 2018.
} 
em cada fotograma fornece as intenções das narrativas duais de modo completo: Fabiene Gama afirma haver inúmeras lacunas nessa história, muito embora se trate de um período em que diversíssimos materiais, especialmente com descrição detalhada dos recursos técnicos e financeiros utilizados, abrem espaço para que ainda caibam "importantes desdobramentos futuros". A fotografia vinha ainda começando a assumir o papel de registro visual e artístico, mas também se apresentava, na época, de modo dominante, com a potencialidade de empregar-se um campo bidimensional de registro realista em favor da compreensão das dificuldades enfrentadas na tarefa de penetração em espaços demasiado dificultosos, como o amazônico, ademais de comprovar-se, assim, estarem sendo empregadas vias humanísticas, compensadoras dos recursos monetários demandados.

A construção da Estrada de Ferro Madeira-Mamoré é um capítulo da História das Comunicações (e estradas) brasileiras, que, no Estado de Rondônia, passou a ter o seu centramento na BR 364, a atravessar o seu território de Leste a Oeste, ainda hoje a coluna vertebral do transporte de gentes e de mercadorias regional, ligando a capital, Porto Velho (e mesmo Manaus, se vier a ser reaberta a BR 319), ao centro-sul do Brasil. Neste sentido, diversos personagens trazem um singular desvio destes trilhos da identidade estatal rondoniana, recentralizando no asfaltamento e conservação desta estrada a matriz do desenvolvimento do Estado, uma vez que a malha ferroviária nunca serviu muito para a sua função produtiva de apoio, conforme o planejado.

É interessante percorrer, ainda que rapidamente, um pouco da biografia do fotógrafo contratado por Percival Farquhar, considerando as escassas informações, ainda por mapear de modo completo em fontes variadas.

Em Neeleman e Neeleman, encontramos, talvez, as mais importantes informações sobre o fotógrafo:

Consta que Dana Bernard Merrill nasceu em New Hampshire - United States of America, em 1877, e, segundo outra versão, no ano de 1888. Consta, ainda, que ele serviu nas Forças Armadas, nas Ilhas Filipinas, em 1900, segundo o censo d aquele ano. Por volta de 1930, Merrill residia em Scarsdale, Westchester, Nova York, com sua esposa Laura, e mantinha um funcionário seu, de nome Elli Peter, como auxiliar próximo. Ainda nos anos 1930 ele trabalhou para House e Garden Magazine e seu nome aparece pela última vez no censo americano de 1942. Na virada do século, Dana Bernard Merrill era fotógrafo profissional trabalhando em Nova York, para onde voltaria depois de deixar o Brasil. Mais tarde, tornou-se profissional dos mais reconhecidos e respeitados dos Estados Unidos, com clientes como 'as 
revistas House e Garden (1933-4:1938); Vanit Fair (1925;1930) e Vogue $(1929-30 ; 1932)^{\prime 8}$.

Com bastante apuro acerca das circunstâncias iniciais da origem do fotógrafo, permite-se aqui entender que havia respeitabilidade no exercício profissional do seu ofício, de tipo jornalístico, por já ter Dana Merrill sido contratado, portanto testado, em outras ocasiões. Claro que estas referências são contrastadas no local de origem, não cabendo aceitar versões diferenciadas, dada a importância do profissional, para a recomendação das realidades historicizadas. Percival Farquhar, contudo, como empresário empenhado em preencher necessidade que considerava importante, lançava mão de um fotógrafo reconhecido, cujo material municiou campanhas divulgadas por jornais e revistas da época, informando sobre a capacidade construtiva das suas empresas, garantindo aos capitalistas financiadores haver potencial de lucros maiores nos investimentos. A fotografia chegava para eternizar um recorte do tempo estritamente visual, mas trazia em si a intencionalidade argumentativa de quem faria esse registro, para o interesse maior do investimento que se consolidasse.

Fabiene Gama, citando o trabalho do antropólogo Edgard Roquette-Pinto, de 1912, explicita que a fotografia ainda era vista "como registro do real", , sendo-nos possível afirmar que as imagens serviriam para que se conhecessem diretamente as informações que pudessem ali estar transmitidas, embora possamos, hoje, dispor de ângulos interessantes a determinado momento cultural, social, econômico e político. A compreensão do contexto de nascimento da fotografia exige um método apropriado de achegamento e de aprimoramento ao uso desse novo modelo. Parece ser a análise políticocultural, proposta pelo interesse político-cultural, a base metodológica que melhor aproximaria o analista da cultura de uma leitura mais completa, porque coaduna o artístico, o cultural, o social, o político, o econômico e o jurídico ${ }^{10}$.

Para este nosso autor, "não há motivo para uma pessoa não radical e inteligente recusar-se a analisar os fenômenos em seus contextos históricos" ${ }^{11}$, e assim, para ele, o normal é que, para que o analista possa entender a mensagem (que a imagem mostra, no

\footnotetext{
${ }^{8}$ NEELEMAN, Rose; NEELEMAN, Gary. Trilhos na Selva. Tradução Ibraíma Dafonte Tavares. São Paulo: BEÎ, 2011. p. 27.

9 GAMA, Fabiene. "Antropologia e Fotografia no Brasil: O Início de uma História (1840-1970)". In: Revista de Antropologia. São Paulo: USP, 2020, V. 5, n.1; agosto, pp. 82-113. https://www.revistas.usp.br/gis/article/view/163363.

${ }^{10}$ EAGLETON, Terry. Depois da Teoria: Um olhar sobre os Estudos Culturais e o Pós-Modernismo. Rio de Janeiro: Civilização Brasileira, 2014.

${ }^{11}$ EAGLETON, Terry. Depois da Teoria: Um olhar sobre os Estudos Culturais e o Pós-Modernismo. Rio de Janeiro: Civilização Brasileira, 2014. p. 29.
} 
fragmento de tempo captado, no nosso caso pela objetiva fotográfica), é necessário que o seu olhar esteja capacitado, culturalmente, no entendimento da época e no local, para haver uma melhor compreensão dos elementos culturais. E, de tal maneira, que o olhar, assim preparado, passará necessariamente pelo conhecimento anterior do instrumental, tal como preconizado ainda por Kossoy, explicitando o método, que, neste sentido, este autor parece construir como um suporte ideal para a compreensão citada:

Toda fotografia foi produzida com uma certa finalidade. Se um fotógrafo desejou ou foi incumbido de retratar determinado personagem, documentar o andamento das obras de implantação de uma estrade de ferro os diferentes aspectos de uma cidade, ou qualquer um dos infinitos assuntos que por uma razão ou outra demandaram sua atuação, esses registros -que foram produzidos com uma finalidade documental- representarão sempre um meio de informação, um meio de conhecimento, e conterão sempre seu valor documental, iconográfico. Isso não implica, no entanto, que essas imagens sejam despidas de valores estéticos ${ }^{12}$.

Não se pode, portanto, nos deter somente no realismo dos efeitos técnicos ou estéticos que uma fotografia tem a revelar, sem levarmos em conta as mensagens completas que se lhe exigem, que somente com sensibilidade detida o analista conseguirá divisar.

Isto posto, tem-se que procurar entender que entre a imagem retratada na fotografia e o objeto que foi fotografado escondem-se aspectos sociais, econômicos, históricos, ideológicos e culturais a serem analisados, de acordo com a opção, o conhecimento e, principalmente, a intenção ideológica e artística do fotógrafo e do analista deste tipo de discurso.

Jean Dubois oferece uma outra perspectiva sobre a fotografia, que qualifica como "ato icônico" ou "ato de sua contemplação":

A foto não é apenas uma imagem (o produto de uma técnica e de uma ação, o resultado de um fazer e de um saber fazer, uma representação de papel que se olha simplesmente em sua clausura de objeto finito), é também, em primeiro lugar, um verdadeiro ato icônico, uma imagem, se quisermos, mas em trabalho, algo que não se pode conceber fora de suas circunstâncias, fora do jogo que a anima sem comprová-la literalmente: algo que é, portanto, ao mesmo tempo e consubstancialmente, uma imagem-ato, estando compreendido que esse ato não se limita trivialmente apenas ao gesto da produção propriamente dita a imagem (o gesto da tomada), mas inclui também, o ato de sua contemplação ${ }^{13}$.

\footnotetext{
${ }^{12}$ KOSSOY, Boris. Origens e Expansão da Fotografia no Brasil. Século XIX. Rio de Janeiro: Funarte, 1980. pp. 47-48.

${ }^{13}$ DUBOIS, Philippe. O Ato Fotográfico e outros ensaios. Tradução Marina Appenzeller. Campinas: Papirus, 1993. p.15.
} 
Claro que não é difícil manter qualquer das perspectivas em separado. Contudo, uma leitura plena de mundo presume reconhecer inexistir o simples: como disse Mario Bunge (q.v.), "existe o simplificado". Uma teoria do discurso será uma ferramenta técnica passível de ser assimilada por uma metodologia científica, de amplas vistas culturalistas, capaz de ir mais fundo do que uma perspectivação de superfície.

Neste sentido, para consolidar o viés discursivo da linguagem, trazemos aqui o instrumental da Análise do Discurso, de Michel Pechêux, que tem por objetivo visualizar de modo privilegiado três regiões de conhecimento bem definidas, como são o materialismo dialético, compreendido como teoria social do fundamento das ideologias, a linguística, oriunda da Semiótica, entendidas como construto sintático fornecedor de elementos e processos de realce das suas partes; e uma teoria do discurso, abarcadas as suas técnicas a serviço da somatória político-cultural da que depende no movimento dialético e contextualizado, espaço-temporalmente.

O pressuposto aqui esposado é que a mensagem exibida pela objetiva fotográfica deve ser entendida como dotada de um propósito persuasivo semiótico amplo. Entre a imagem retratada na fotografia e o objeto fotografado espelham-se, escondem-se e superpõem-se aspectos que apenas uma mirada político-cultural será capaz de revelar mais plenamente, desviando-se dos anacronismos, realçando-se os caracteres históricos e ideológicos interessantes na época à pessoa do contratante e do especialista nas artes da sedução aos financiadores.

Orlandi, no seu livro Análise de Discurso, afirma que "o discurso é um lugar em que se pode observar essa relação entre língua e ideologia, compreendendo-se como a língua produz sentidos por/para sujeitos" ${ }^{\text {"14 }}$. Entendemos ser a fotografia também uma forma de discurso que produz sentidos pelos sujeitos e para sujeitos. Portanto, a simples análise dos elementos de composição da fotografia pouco acrescentaria neste estudo, de vertente culturalista, porquanto desvendar a estrutura é apenas o primeiro passo para a compreensão do mundo discursivo.

A discursividade nas fotografias se manifesta por elementos ideológicos (políticos), econômico e cultural, somente para citar três âmbitos, que estão embutidos na fotografia. Com isso, percebe-se que a análise da produção das fotografias de Dana Merrill deve ser contextualizada e compreendida nos marcos propagandísticos da Estrada Ferro MadeiraMamoré, a partir de uma perspectiva político-econômica. Claro que, ao perceber que está

${ }^{14}$ ORLANDI, Eni Puccinelli. Discurso em Análise: Sujeito, Sentido, Ideologia. Campinas: Pontes, 2012. p.111. 
em uma fronteira civilizacional diferenciada, pela força dos elementos e pela vibração das necessidades, sem falar no que exsurge em termos de origens dos tipos humanos, um contato de origens diversas com os autóctones e ainda com os próprios colonos brasileiros, em condições muito específicas de convivência, Dana Merrill procura retratar a saga, através das suas lentes, querendo por um lado contemplar o pleito do empresário, era o seu dever, mas por outro lado demonstrando interesse em difundir um ideal de colonização tecnológica, no embate impactante que se dava entre a natureza e a perseverança humana.

Aquilo que chama a atenção nas fotografias, primeiramente, é a capacidade que elas têm de, através do sentido da visão, atrair, levar, por exemplo, a um passeio sinestésico, quando se depara com uma fotografia antiga, ainda mais -e tudo parece mais nítido, embora menos próximo, também menos irreal, tal como enfatizava Dubois, acima citado.

A fotografia, portanto, tem a capacidade de eternizar, em um clique, o registro de algo que nunca mais será repetido com a mesma fidelidade, mesmo se tratando do registro de um objeto estático, pois, em um segundo momento, algo em sua volta estará mudado, e essa transmutação, mesmo com o espaço de alguns instantes, mudará o sentido visual que se quereria constatar.

Não distava muito, na vivência de Dana Merrill, a primeira tentativa de "arte na fotografia": Deu-se na França no início da década de 1860, quando os fotógrafos de estúdio perceberam que podiam acrescentar às suas fotografias algo novo que viesse a valorizar mais ainda o seu trabalho. Surgiu então o retoque às imagens, retoque feito no negativo, e ainda a fotopintura, que consistiu na pintura efetuada no retrato já revelado. Kossoy assim se refere a este momento:

A fotopintura consistia justamente de uma representação ambígua obtida pelo trabalho misto do fotógrafo e do pintor; o retrato do cliente era inicialmente obtido por meios fotográficos numa carte de visite e posteriormente ampliado sobre tela ou papel e então pintado. O novo artifício estético representou mais uma possibilidade de diferenciação social para que um pequeno seguimento da sociedade não fosse confundido com os clientes consumidores de retratos fotográficos convencionais ${ }^{15}$.

Até a chegada do século XX, conforme se vê em Novaes, a fotografia não era admitida como arte, representava "o registro do real", como se disse acima. Somente com o surgimento da definição estética do que era "arte contemporânea", ela começou a

\footnotetext{
${ }^{15}$ KOSSOY, Boris. Origens e Expansão da Fotografia no Brasil. Século XIX. Rio de Janeiro: Funarte,
} 1980. p. 46. 
ganhar espaço dentro de novas concepções oriundas do rompimento com as formas de análise do que seria um ato de criação ${ }^{16}$.

Atualmente, é comum verificarmos a exposição de fotografias ocupando o espaço dos museus, mormente quando as fotos são feitas trazendo um sentido de arte como objetivo, e transmitindo emoções, influências e mensagens, e mostrando a sensibilidade artística de quem a criou.

Analisando as fotografias de Dana Merrill, é difícil separar nelas o artista do profissional, pois nota-se em todas o cuidado na escolha dos objetos e das paisagens; o ângulo certo no posicionamento da máquina, e a claridade, levando em conta o horário em que foram feitas as fotos, já que quase a totalidade delas aconteceu em ambiente externo e, por isso, o seu cuidado com a sombra e com a incidência de raios ultravioleta a merecer uma atenção especial.

O trabalho de Dana Merrill, ainda que sendo executado com um artefato mecânico e de maneira artesanal, demonstra carinho e zelo especiais, características típicas do bom profissional que ele era. Não podemos olhar uma fotografia feita por Merrill sem identificarmos nela a fusão entre a arte e a vida, a liberdade artística e as intenções do autor e sem que haja a interação do espectador com a obra, características marcantes da arte contemporânea.

Depois de entendermos a fotografia como um registro visual e artístico, chegamos à conclusão de que Dana Merrill foi um excelente profissional e as imagens feitas por ele, embora apresentando um campo bidimensional, nos ajudam a entender o seu profissionalismo e a sua arte, mesmo nas condições insalubres em que elas foram realizadas.

Para quem imaginar o trajeto por onde deveria ser construída a ferrovia, no início do século XX, coberta pela floresta amazônica, densa e de difícil penetração, pode fazer uma ideia do primeiro contato de um norte-americano com esse mundo onde o calor e a umidade do ar, os insetos e tudo à sua volta esconde um perigo constante ameaçando a sua vida.

Os cipós constituem o mais sério obstáculo ao nosso trabalho. Variam eles, em diâmetro, desde $7 \mathrm{ou} 10 \mathrm{~cm}$ até fios bastantes finos que oferecem a resistência do couro. Pode-se ter ideia de como é difícil abrir caminho através da mata, sabendo-se que com cinco lenhadores, o maior percurso que conseguimos fazer em um dia foi de pouco mais de um quilômetro, quando nos Estados Unidos conseguíamos de 6 a 8

\footnotetext{
${ }^{16}$ NOVAES, Sylvia Caiuby (Org.). Entre Arte e Ciência: A Fotografia na Antropologia. São Paulo: Edusp, 2015. p. 15
} 
quilômetros por dia através do mato. Nós, nos Estados Unidos, nos entusiasmamos com as florestas luxuriantes dos trópicos, mas, quando nelas nos enredamos e verificamos que não conseguimos alongar a vista por mais de três metros em qualquer direção, nosso entusiasmo logo arrefece. Causou-nos desapontamentos o reduzido número de animais selvagens e cobras que tivemos ocasião de ver, mas há uma espécie de praga com que não contávamos e que não dá descanso de forma alguma: as formigas ${ }^{17}$.

Foi nesse mundo que Dana Merrill viveu durante quatro anos e produziu, segundo vários autores, mais de duas mil fotografias das várias etapas da construção da Ferrovia Madeira-Mamoré, viajando de trem, de lancha, em lombo de burros e a pé, visitando os acampamentos e a eles, muitas vezes, chegando altas horas da noite, carregando o seu precioso equipamento fotográfico ${ }^{18}$.

Nesse ambiente, repleto de dificuldades, a intuição do fotógrafo Merrill soube separar a arte do simples registro iconográfico para nos legar um acervo histórico de imensa valia, pois nele encontramos desde o registro dos indígenas, dos doentes, dos acidentes, do progresso, de uma cidade nascendo sem língua e sem cultura própria até o registro político-social onde a elite dominante do capitalista empreendedor é contrastada com a classe proletária dos trabalhadores de várias nacionalidades. Daí merece destaque a manifestação de Manuel Rodrigues Ferreira quando escreve que: "Nunca, em nenhum lugar do mundo, uma obra de engenharia civil foi tão fotografada e com tanta técnica e arte fotográfica como ele o fez - sobretudo com amor à arte" ${ }^{\text {19 }}$.

De todo o valioso acervo fotográfico produzido por Dana Bernard Merrill, apenas trezentas fotos foram selecionadas por Percival Farquhar, escolhidas não pela qualidade artística, profissional ou histórica, mas possivelmente pela mensagem humanística e pelas dificuldades que elas pudessem mostrar, ademais do potencial de atração para futuros investidores estrangeiros.

O objetivo dessa escolha não foi o de formar um acervo fotográfico, destinado a fazer parte da História da Companhia, e sim o de usar imediatamente como meio de convencimento junto a outros capitalistas financiadores, visando a obtenção de recursos em futuros empreendimentos, já projetados para as imensas áreas de terras obtidas por

\footnotetext{
${ }^{17}$ CRAIG, Neville B. Estrada de Ferro Madeira-Mamoré: História Trágica de uma Expedição. Tradução de Moacir N. Vasconcelos. São Paulo: Companhia Editora Nacional. 1947. p. 214.

${ }^{18}$ FERREIRA, Manoel Rodrigues. Ferrovia do Diabo. São Paulo: Editora Melhoramentos Ltda, 2005. pp. 12-13.

${ }^{19}$ FERREIRA, Manoel Rodrigues. Ferrovia do Diabo. São Paulo: Editora Melhoramentos Ltda, 2005. p. 13.
} 
compra e em concessões, delegadas pelo governo federal nas terras dos atuais estados de Rondônia e de Mato Grosso.

A qualidade das máquinas, a estratégia utilizada, a maneira humanística, retratadas intencionalmente nas fotografias, o modo flagrado de tratamento dos indígenas e dos doentes atendidos em um hospital então moderno, inteiramente a serviço do trabalhador, e uma cidade que surgia no meio da maior floresta tropical do mundo, eram motivos suficientes para convencer o mais avaro dos empreendedores.

O trabalho fotográfico de Merrill deve ser entendido, portanto, com um propósito semiótico dual, carregado de poder de convencimento pela representatividade visual icônica, apontando para as dificuldades da construção e para a capacidade técnica de vencê-las como superação dos limites da pessoa humana; mostrando-nos o hospital da Candelária que, por ligação aponta para a maneira eficaz e humana com a qual eram tratados os trabalhadores e para uma Estrada de Ferro Madeira-Mamoré, símbolo de um progresso construído em plena selva amazônica.

O trabalho fotográfico de Dana Merrill permite-nos divisar a possibilidade de que cada retrato seja analisado sob os mais variados ângulos investigativos. Neste sentido, o nosso estudioso da linguagem fotográfica esclarece o enfoque do trabalho em geral:

As fontes fotográficas são uma possibilidade de investigação e descoberta que promete frutos na medida em que se tentar sistematizar suas informações, estabelecer metodologias adequadas de pesquisa e análise para decifração de seus conteúdos, e por consequência, da realidade que os originou" 20 .

Quando Percival Farquhar escolheu as fotos obtidas por Merrill, possivelmente ele buscou selecionar (segundo se dirime de Barthes, 1984) as mensagens codificadas de cada uma delas, mas selecionando aquelas que poderiam conter fatores conotativos, capazes de facilitar o convencimento dos capitalistas investidores.

Pode-se até admirar uma foto pelo que ela representa, mas devemos ter em mente que isso não é tudo e, através de uma análise político-cultural pode-se achegar a descobrir melhor as informações sociais, históricas e ideológicas escondidas no jogo de nitidez, luz e sombra que a imagem em primeira mão passa a nos mostrar. A tipologização das fotografias permite recriar o ideal da mensagem ou das mensagens solicitadas pelo empresário.

${ }^{20}$ KOSSOY, Boris. Origens e Expansão da Fotografia no Brasil. Século XIX. Rio de Janeiro: Funarte, 1980. p. 32 . 
Isso será tratado oportunamente, noutra parte, sendo importante dizer da necessidade de obter o tripé básico do processo comunicativo, qual seja, o emissor, no caso o empresário Farquhar, muito embora as fotos sejam de autoria de Merrill; a mensagem argumentativa planejada, não obstante sejam elas veiculadas pelas imagens capturadas em campo; e o destinatário, que não se tratava, já se sabe, cada retrato de diapositivas para a eternidade, mas sim possuíam objetivo bem pragmático, visando calafetar o caminho da continuidade de um negócio empresarial.

É curioso como os mais relevantes trabalhos de pesquisa costumam dar mais valor aos pressupostos metodológicos do que mais propriamente ao objeto abordado. É claro que o detalhamento do objeto, a sua adequada referenciação, é fator importante para uma resultante mais concreta. É primeiro, mas certamente não será objetivamente o mais relevante centro do trabalho.

No nosso caso, trata-se de dar ênfase à importância da mensagem das fotos contratadas por um empresário de começo do século $\mathrm{XX}$, marcadas porém pelo fator argumentativo da busca de financiamentos para a construção da Estrada de Ferro Madeira-Mamoré. Já havia, na época, um passado de dificuldades, fracasso, ameaça de falência, de comprovação perante o governo para obter recursos mais além do que na Amazônia.

O investimento pontual, "naquele fim de mundo", era apenas um referencial grandiloquente. Obter financiamento era uma dificuldade maior em todos os recantos, sendo aquela empreitada somente uma base mais vistosa. Não era objetivo-fim do empresário a construção da Estrada de Ferro, mas sim os lucros que seriam obtidos na compra da tecnologia, no mais-valor obtido dos serviços contratados a centenas e centenas de trabalhadores, recrutados com origem planetária variadíssima.

Assim, ao lado da ênfase à importância do "registro do real" das fotos, torna-se importante o contexto, e, portanto, visualizá-las como objeto de discurso, passível, pois, de uma espécie de análise do discurso que visibilize o conjunto discursivo. Para Pêcheux (2016), há condições concretas nas quais se dão os processos discursivos, sempre estribados na História, centrada esta no poder ou em alguma ideologia, e nunca sendo um absoluto do intérprete, a quem exige-se haver base em uma afirmação de outro ou em uma realidade dada por outrem, caso contrário torna-se "uma questão de ética e política: uma questão de responsabilidade" ${ }^{21}$.

\footnotetext{
${ }^{21}$ PÊCHEUX, Michel. O Discurso: Estrutura ou acontecimento. Campinas: Pontes, 1990. p. 57.
} 
Este viés discursivo, que alcança o âmbito dual de Dana Merrill, passou a ser o mais interessante enfoque, para podermos divisar com amplitude de vistas metodológicas esse acontecimento grandioso e insólito que é essa empresa amazônica de engenharia plurinacional -sem centramento no seu (frustrado) objetivo-fim: a lucratividade do transporte de produtos da Bolívia de um lado a outro do continente sul-americano, dado o bloqueio da saída pelo Oceano Pacífico. Há uma leitura de propósitos detrás das palavras, nelas mesmas, mas também na situação. Quando trabalha as agruras da vivência sob o apartheid sul-africano, Homi Bhabha explica que palavras falam menos -ou nem falam, pois "as palavras não falarão e o silêncio congela-se em imagens do apartheid" 22 . Para este analista da cultura, devem-se vigiar os usos: "as carteiras de identidade, provas forjadas pela polícia, fotografias para fichas de presídio, os retratos reticulados de terroristas na imprensa" 23 , sendo a intencionalidade do uso aquele característico que mais empresta valor. De uma maneira ou de outra, ressalta-se sempre uma visão típica e idealista do colonizador, que se impõe pelo seu discurso, porque ele o dispõe.

Esta leitura de propósitos, muitas vezes escondidos por detrás das palavras, analisando-se a perspectiva político-cultural, viés objetivado pelo produtor/comprador da mensagem, logra verificar uma rede de intencionalidades duplas havidas na produção das fotografias, ao longo dos quatro anos em que Dana Merrill esteve, de fevereiro de 1909 a agosto de 1912. Assim, se trata de perfazer aqui o trânsito de uma análise cultural, sem que, contudo, nada impeça que outros tipos de análise possam emprestar instrumentos para observar mais de perto o detalhamento preferido no discurso fotográfico. Ao final, apresentaremos algumas fotografias que exemplificam a presença constante de uma dualidade discursiva de Dana Merrill que servirá para visualizar todos os acervos com os milhares de retratos realizados.

Com efeito, de todas as demais possibilidades, está a Análise do Discurso, técnica vitoriosa que estamos esposando em complemento ao método analítico político-cultural, suficientemente contrastada por práticas mil, no Brasil, na França ou em quaisquer dos países onde se empregou a sua alavanca vigorosa e rigorosa, o corpo instrumental de Pechêux torna-se a mais recomendável, porquanto soma-se decisivamente aos primados da interpretação político-cultural que deve ser desvelada no momento seguinte da

\footnotetext{
${ }^{22}$ BHABHA, Homi. O Local da Cultura. Tradução de Myriam Ávila, Eliana Lourenço de Lima Reis e Gláucia Renata Gonçalves. Belo Horizonte: Editora da UFMG, 1998.

${ }^{23}$ BHABHA, Homi. O Local da Cultura. Tradução de Myriam Ávila, Eliana Lourenço de Lima Reis e Gláucia Renata Gonçalves. Belo Horizonte: Editora da UFMG, 1998.
} 
caracterização das partes do discurso, da tipologização temática das fotos, da categorização discursiva das intenções do fotógrafo.

Claro que os aspectos teóricos hauridos de Bhabha, com as teorias pós-coloniais centradas no objeto, a perspectiva de Terry Eagleton, de caráter político-cultural, abrangendo o método para além do objeto, passam a cobrar uma fatura bidimensional decisiva.

O caminho para a interpretação é inverso ao da análise discursiva realizada: Sabese da necessidade de persuadir... investidores. As perguntas que fazemos nós, contemporaneamente, assim como as fazia o contratante Percival Farquhar, é: Valeu o esforço dinheirário? As trezentas fotos selecionadas conseguem mostrar os motivos grandiosos do financiamento? Pode-se, por elas, obter incremento no preçamento do quilômetro linear da ferrovia construída?

Com respostas positivas, percebe-se que conferir ao discurso histórico-visual (portanto, não somente linguístico, mas semiótico) essa capacidade de alcance às respostas certas, ressalta esse importante âmbito teórico-discursivo como base para obter material a efetuar uma análise do discurso modalizadora, no âmbito político-cultural, ou seja, cujo viés metodológico talvez seja o mais importante referencial neste trabalho, mas não deixa encoberto o objeto, muito pelo contrário: ressalta-o melhor.

Muito provavelmente sem a Análise do Discurso que bem auxiliou a esquadrinhar (politicamente, culturalmente e mais) cada fotograma, caracterizando os motivos, teríamos mais que nada uma perspectiva impressionista de tipo historicista vago, típica do senso-comum, uma espécie qualquer de "parecer", muito mais apropriado ao jornalismo que aos interesses da Retórica, muito mais do tipo divulgativo do que de matriz científica, bem mais estudantil do que filológico-interpretativo.

A Análise do Discurso, se recortado adequadamente o seu instrumental dentre tantas ferramentas que propicia, por muitos e inúmeros apóstolos e teóricos, é capaz de conferir essa cientificidade e esse calor, essa certeza da adequação e essa resultante forte, e com isso privilegiar o objeto como eixo discursivo, tornando o método algo nuclear mas bem disfarçado no corpo dissertativo do esclarecimento das pessoas sobre aquilo que se esconde debaixo do nariz do desconhecimento daquilo (nem sempre) evidente.

O final imediato do empreendimento da Estrada de Ferro Madeira-Mamoré, tão logo seria possível levar a cabo um uso dos trechos concluídos, dado o sucesso do empreendimento da borracha no Oriente, que levou todos no Brasil do látex à falência, tornou tanto impossível como desnecessário avaliar o sucesso da vertente argumentativa 
de Dana Merrill nesta atividade de configuração da arte fotográfica como elemento político-cultural persuasivo nessa construção discursiva pelas suas fotografias. Contudo, até hoje, resiste na leitura das fotografias de Dana Merrill essa segunda intenção da sua dual perspectivação profissional, profundamente colonialista: $\mathrm{O}$ empreendimento da Estrada de Ferro Madeira-Mamoré teria sido mesmo uma saga que testou a fibra de gentes, oriundas de todo o mundo, que enfrentou, com diferentes resultados, a Natureza, na última fronteira da Civilização e do emprego de tecnologia de países centrais.

Data de submissão: 01/09/2020

Data de aceite: 05/11/2020 


\section{Referências Bibliográficas}

ALMEIDA, Alfredo Vagner Berno de (Org.). "Conflitos sociais no "Complexo Madeira".” In: Projeto Nova Cartografia Social da Amazônia. Manaus: UEA Edições, 2009. Disponível em: https://www.academia.edu/9030621/Conflitos_sociais_no_Complexo_Madeira_; Acesso em: 14 jun. 2020.

ASHMEAD, P. H. Bulletin of the Pan American Union. Vol. XXXII. January-June, Washington, D.C., 1911.

BARTHES, Roland. A Câmara Clara: Tradução de Júlio Castañon Guimarães. Rio de Janeiro: Nova Fronteira, 1984.

BHABHA, Homi. O Local da Cultura. Tradução de Myriam Ávila, Eliana Lourenço de Lima Reis e Gláucia Renata Gonçalves. Belo Horizonte: Editora da UFMG, 1998.

BUNGE, Mario. Teoria e Método. São Paulo: Perspectiva, 1974.

CRAIG, Neville B. Estrada de Ferro Madeira-Mamoré: História Trágica de uma Expedição. Tradução de Moacir N. Vasconcelos. São Paulo: Companhia Editora Nacional. 1947.

DUBOIS, Philippe. O Ato Fotográfico e outros ensaios. Tradução Marina Appenzeller. Campinas: Papirus, 1993.

EAGLETON, Terry. Depois da Teoria: Um olhar sobre os Estudos Culturais e o PósModernismo. Rio de Janeiro: Civilização Brasileira, 2014.

EAGLETON, Terry. As Ilusões do Pós-Modernismo. Tradução Elisabeth Barbosa. Rio de Janeiro: Zahar, 1996.

FERREIRA, Manoel Rodrigues. Ferrovia do Diabo. São Paulo: Editora Melhoramentos Ltda, 2005.

GAMA, Fabiene. “Antropologia e Fotografia no Brasil: O Início de uma História (18401970)". In: Revista de Antropologia. São Paulo: USP, 2020, V. 5, n.1; agosto, pp. 82113. https://www.revistas.usp.br/gis/article/view/163363.

GAULD. Charles Anderson. Farquhar. O Último Titã. Tradução Eliana Nogueira do Vale. São Paulo: Editora de Cultura, 2006.

KOSSOY, Boris. Origens e Expansão da Fotografia no Brasil. Século XIX. Rio de Janeiro: Funarte, 1980.

KOSSOY, Boris. Fotografia \& História. 2a Edição Revisada. São Paulo: Ateliê Editorial, 2001.

NEELEMAN, Rose; NEELEMAN, Gary. Trilhos na Selva. Tradução Ibraíma Dafonte Tavares. São Paulo: BEÎ, 2011.

NEWHALL, Beaumont. História de la Fotografía. Barcelona: Ingoprinte S.A., 2002 
NOGUEIRA, Júlio. Estrada de Ferro Madeira-Mamoré. Rio de Janeiro: Typographia do Jornal do Comércio, 1913.

NOVAES, Sylvia Caiuby (Org.). Entre Arte e Ciência: A Fotografia na Antropologia. São Paulo: Edusp, 2015.

OLIVEIRA, Ariovaldo Umbelino. Amazônia: Monopólio Expropriação e Conflitos. São Paulo: Papirus, 1995.

ORLANDI, Eni Puccinelli. Discurso em Análise: Sujeito, Sentido, Ideologia. Campinas: Pontes, 2012.

PÊCHEUX, Michel. Semântica e Discurso: uma Crítica à Afirmação do óbvio. São Paulo: Contexto, 2016.

PÊCHEUX, Michel. O Discurso: Estrutura ou acontecimento. Campinas: Pontes, 1990.

SANTOS, Evandro e BIAZO, Glauber Cícero Ferreira. In: "Teoria da História e História da Historiografia: Debates e desafios do conhecimento histórico no século XXI" / Dossiê. V. 10 n. 1 (2018). Canoa do Tempo. Revista do Programa de Pós-Graduação em História da Universidade Federal do Amazonas (UFAM). Manaus: UFAM, 2018. 


\section{ANEXO \\ Imagens que ilustram as análises apresentadas}

Estes breves exemplos a seguir, dividimo-los no que chamamos de "a dupla construção discursiva da EFMM", ou seja, o viés do sucesso, explicando a justa aplicação dos recursos financeiros captados, e o viés da "saga", no combate aos elementos da Natureza, isto é, o ideal de colonização tecnológica, na força da perseverança humana, a típica visão idealista do colonizador forâneo (BHABHA).

A fonte das fotografias é o acervo próprio do Professor Antônio Cândido da Silva, que trabalhou na EFMM, nos anos de 1962 a 1963, e que possui desde a década de 1960 centenas de fotogramas, depois tratados e difundidos amplamente na internet, e repetidas as fotos a partir de originais hoje pertencentes ao Acervo Iconográfico do Museu do Ipiranga, que está acoplado ao Museu Paulista da USP, doado esse material pelo BNDES apenas em 1999, como se pode ver em http://www.mp.usp.br/museu-paulista-da-usp.

Foto 1: Obra de engenharia: superação do hiato fluvial

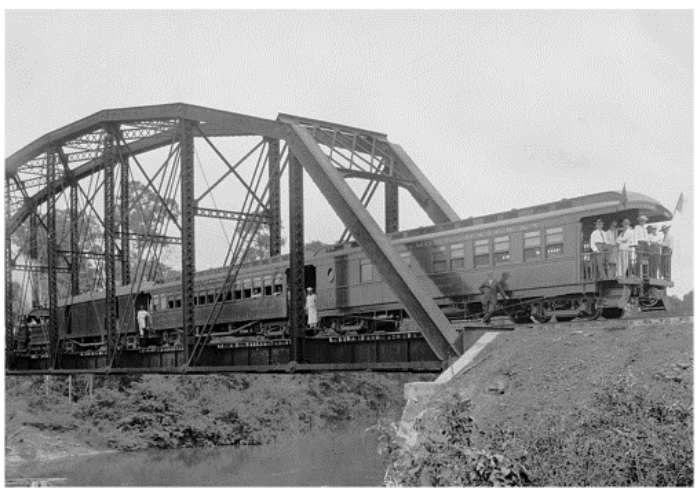

Foto 2: Obra de engenharia: atravessando a barreira rochosa

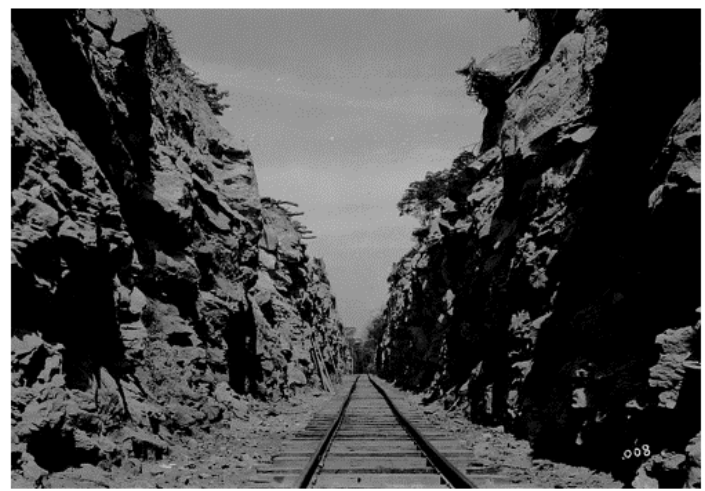


Foto 3: Obra de engenharia: uma derrota para as forças naturais

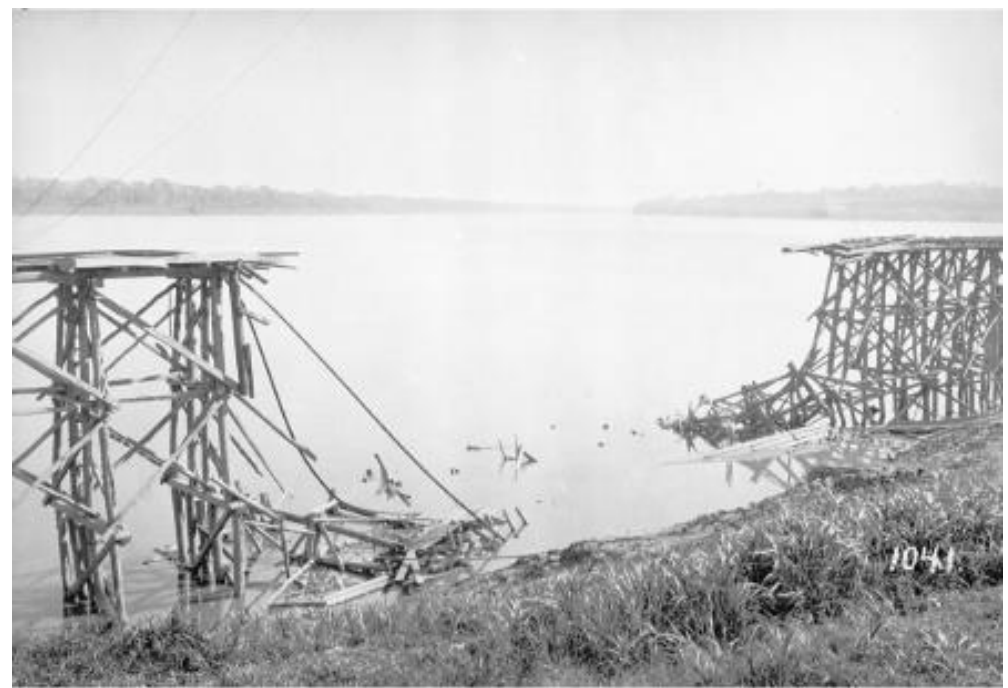

Desabamento do Cais de Porto Velho em Construção à margem do Rio Madeira - 1041, Acervo do Museu Paulista da USP

Foto 4: Obra de engenharia: chuvas e alagamentos constantes

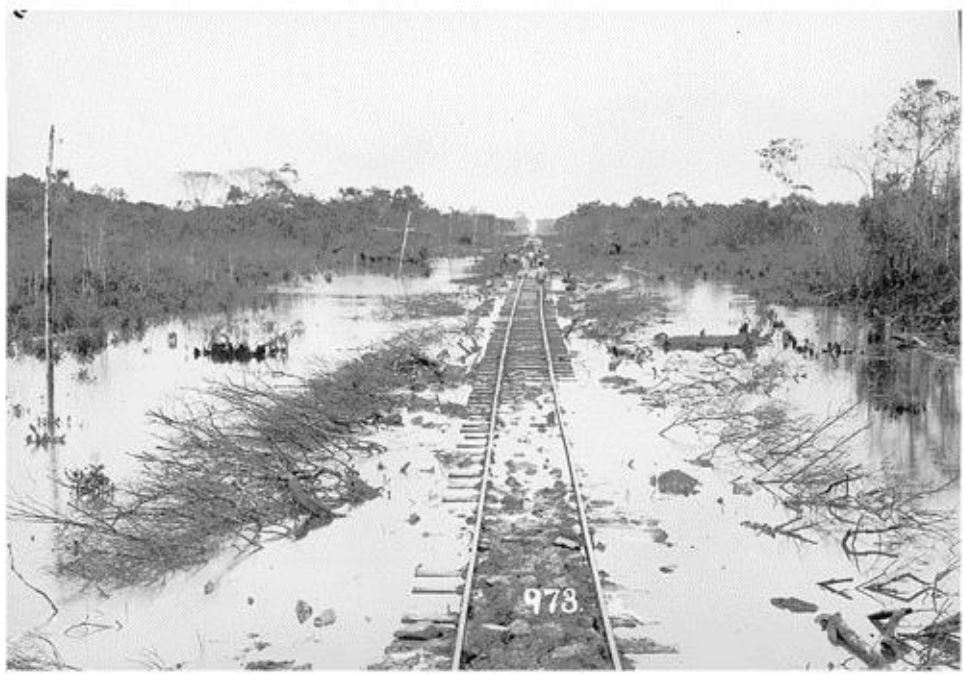

Na Época da Cheia do Rio Madeira Suas Águas Sobem 14 M. Acima da Taxa Mínima Pluviométrico - 973, Acervo do Museu Paulista da USP 
Foto 5: Cemitério: derrotas parciais com pagamento em vidas humanas

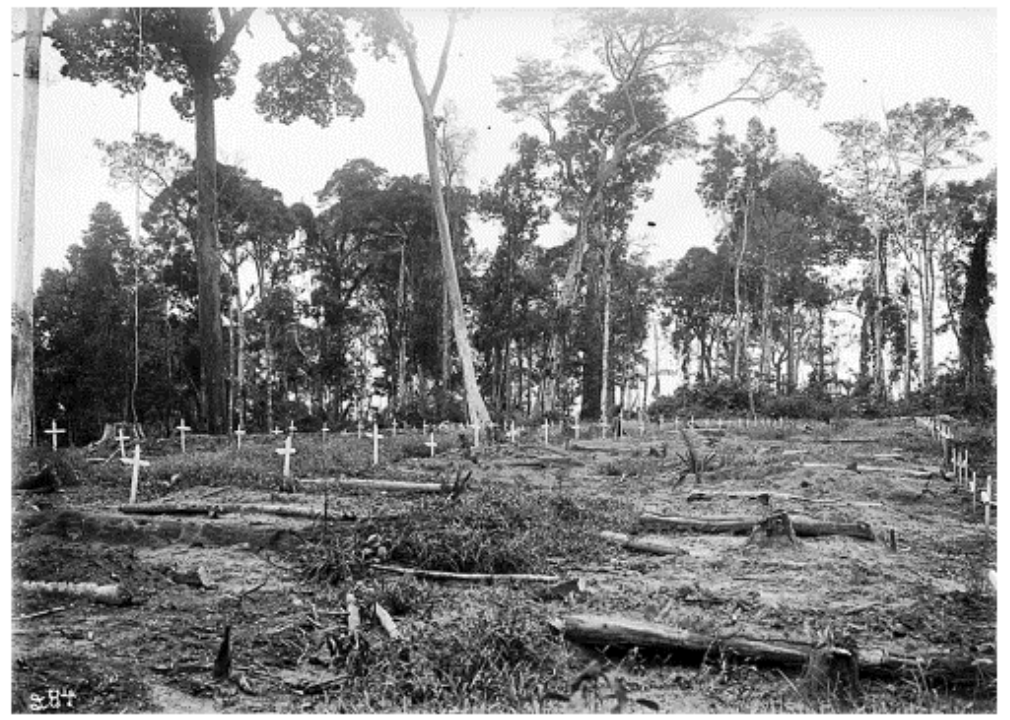

Foto 6: Importação de máquinas e equipamentos, em geral da Inglaterra ou EUA

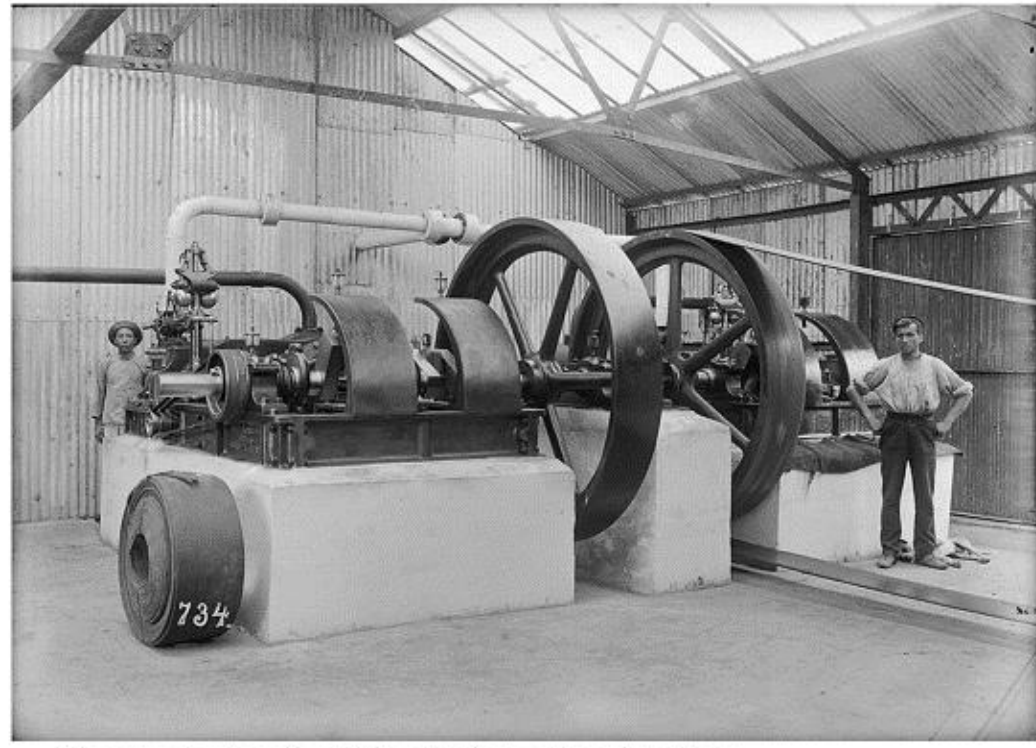

Gerador de Energia Elétrica Movido a Óleo Cru. Porto Velho - 734, Acervo do Museu Paulista da USP 
Foto 7: Investimento em saúde: O Hospital da Candelária recebia constantes suprimentos e pessoal especializado

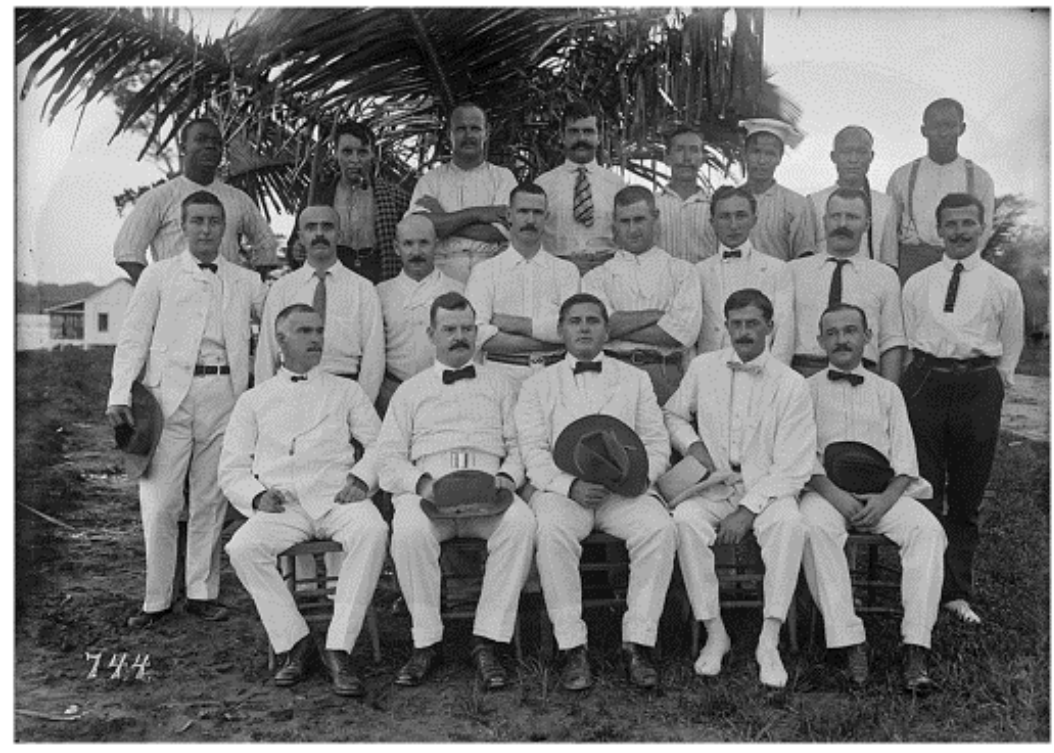

Grupo de Médicos e Enfermeiros do Hospital Candelária - 744, Acervo do Museu Paulista da USP 